\title{
Ters-Yüz Edilmiş Sınıf Modelinin Öğretmen Adaylarının Erişileri ve Görüşleri Açısından İncelenmesi*
}

\author{
Derya GÖĞEBAKAN YILDIZ $\quad$ Gülbin KIYICI ${ }^{* * *}$ \\ Gülşen ALTINTAŞ Ş** $^{* * *}$
}

Öz

\begin{abstract}
Araştırmanın amacı kimya öğretiminde kullanılan ters yüz edilmiş sınıf (TES) modelinin öğretmen adaylarının erişileri ve görüşleri açısından incelenmesidir. Çalışmada, nicel ve nitel veri toplama yöntemlerinin birlikte kullanılması yoluyla, araştırma sonuçlarını bütünleştirilmesine imkan sağlayan karma yöntem kullanılmıştır. Araştırma Deney (N:21) ve Kontrol (N:18) grupları olmak üzere toplam 39 Fen Bilgisi öğretmen adayı ile yürütülmüştür. Deney ve kontrol gruplarına işlem öncesi ön test ve işlemler sonrasında da son test olarak araştırmacılar tarafından geliştirilen, "Genel Kimya Başarı Testi" ayrıca tersyüz sınıf etkinliklerine ilişkin sürecin daha iyi açıklanması amacıyla öğretmen adaylarına dört maddelik bir görüş formu uygulanmış ve elde edilen veriler analiz edilmiştir. Sonuç olarak, deney grubunda Genel Kimya-1 dersinin öğretiminde kullanılan TES modelinin öğretmen adaylarının erişileri üzerinde anlamlı bir etkisi olduğu söylenilebilir. Ayrıca öğretmen adayları TES modeli uygulamalarına ilişkin önemli oranda olumlu görüş belirttikleri ve modeli etkili buldukları saptanmıştır.
\end{abstract}

Anahtar Kelimeler: Kimya öğretimi, ters-yüz edilmiş sınıf modeli, akademik başarı, erişi, öğretmen adayları.

\section{A Research into the Flipped Classroom in terms of the Academic Achievement, and Views of the Prospective Teachers}

\begin{abstract}
\footnotetext{
* Bu çalışma, 25. Ulusal Eğitim Bilimleri Kongresi'nde sözlü bildiri olarak sunulmuştur.

** Yrd.Doç.Dr., Celal Bayar Üniversitesi, Manisa-Türkiye, dgogebakan@yahoo.com

*** Öğr.Gör., Celal Bayar Üniversitesi, Manisa-Türkiye, gulbin.kiyici@gmail.com

**** Öğr.Gör.., Celal Bayar Üniversitesi, Manisa-Türkiye, gulsenaltintas@mynet.com
}

The aim of this research is a study of the flipped classroom used in chemistry education in terms of the academic achievement and views of the prospective teachers. In the study, mix method was used. Including the research experiment (N:21) and control (N:18) groups, it has been carried out with the 39 prospective science teachers. "General Chemistry Achievement Test" which have been developed by the reserchers before process as the pre test and after the process post test o the experiment and control groups, also with the aim of flipped classroom activities related process in mind, has been practiced to the prospective teachers in the form of a view form of four articles and the resulting data have been analized. As a result, it can be said there is an effect of the flipped classroom on General Chemistry-1 in the experiement group on the academic achievement of the 
prospective teachers. Moreover, it has also been found that the prospective teachers have opined in positive regarding the flipped classroom activities and they have found the method effective.

Keywords: Chemistry education, flipped classroom, academic achievement, prospective teachers.

\section{Gíriş}

Bilim ve teknoloji alanındaki gelişmeler ekonomiden sağlığa, sanattan edebiyata tüm alanları önemli değişimlere zorlamaktadır. Teknolojik gelişmelerden en fazla etkilenen ve paradigmalarını dönüştürmesi beklenen bir diğer alan ise eğitimdir. Söz konusu değişimden en önemli payı $Z$ kuşağı ya da dijital vatandaş (Prensky, 2001) olarak anılan çocuklar ve gençler almaktadır. Bu bireylerin en önemli özelliği yaşamlarına teknolojiyi çok daha hızlı adapte edebiliyor olmalarıdır. Nitelikleri bakımından, kendinden önceki kuşaktan önemli oranda farklılaşan bu öğrencilerin yetiştirilmesinde eğitim teknolojilerinden etkili bir şekilde faydalanılması bir gereklilik olarak görülmektedir (Orhan, Kurt, Ozan, Vural \& Türkan, 2014). Bu durum, eğitimde farklı yöntem ve araçların geliştirilmesini ve kullanılmasını önemli bir ihtiyaç haline getirmektedir.

Eğitim teknolojisi alanında güncel olarak kullanılan yöntemlerden biri de ters yüz edilmiş sinif (flipped classroom) modelidir. Ters-yüz edilmiş sınıf (TES) modeli, öğreten merkezli ve sınıf duvarlarıyla sınırlandırılmış geleneksel eğitim anlayışının tersine çevrildiği, harmanlanmış (blended) bir öğrenme sürecidir. Öğretmen merkezli geleneksel yaklaşımda, bir konu öğretmen tarafından sınıf ortamında aktarılır, konunun özümsenmesi ise öğrenci tarafından çoğunlukla sınıf dışı süreçlerde ve ev ödevi uygulamalarıyla sağlanır. TES modelinde ise öğrenciler, öğretici tarafından hazırlanan ders videolarını ve diğer e-materyalleri ders öncesinde evde, yurtta vb. inceler ve izlerler, sinıfta ise farklı aktif öğrenme etkinlikleriyle konuyu özümseyerek yapılandırırlar. Bu bakımdan geleneksel eğitim sürecinin tersine işleyen bir öğrenme yaklaşımıdır (Bishop ve Verlager, 2013; Görü Doğan, 2015)

TES öğrencilerin sunum materyallerine videolar ya da farklı dijital medya gibi çeşitli iletişim ve öğretim teknolojileriyle ders öncesinde buluştukları ve böylece sınıf içi zamanın tartışmalar, analizler ve problem çözme etkinlikleriyle geçirildiği öğretmeyi tersine çeviren bir yaklaşımdır (Youngkin, 2014). TES modeli öğrencilerin derse daha hazır gelmesini ve öğrendiği kavramları ders içi süreçlerde uygulamasına fırsat verir öğretmen zamanın çoğunu takip etme ve düzeltme işlemlerine ayırır (Sage ve Sele, 2015).

Bishop ve Verlager, (2013) TES modeli üzerine yapılan çalışmaları inceledikleri araştırmalarında, öğrencilerin, ders içi sunumları video sunumlarına diğer taraftan da sınıf içi etkileşimli aktiviteleri, düz anlatıma etkinliklerine tercih ettiklerini ayrıca, ters yüz edilmiş sınıf uygulamalarının geleneksel yöntemlere göre öğrencilerin öğrenmeleri üzerinde daha etkili olduğu sonucuna ulaşmışlardır. Ancak araştırmacılar TES modeli konusunda oldukça az sayıda araştırma olduğunu ve bunlarında öğrencilerin öğrenme ürünlerinin objektif olarak değerlendirilmesinde yeterli olmadığını bu alanda daha fazla sayıda deneysel çalı̧̧maya ihtiyaç duyulduğunu belirtmektedirler.

İlgili alanyazın incelendiğinde TES modeli dünyada 2000'li yılların başlarından itibaren, Türkiye'de ise son dönemlerde çalışıldığ anlaşılmaktadır. Alanyazın taramaları sonucunda dünyada matematikten (Maxson ve Szanislo, 2015; Naccarato ve Karakok, 2015), sağlığa (Sharma, Lau, Doherty, Harbutt, 2015; Youngkin, 2014) yönetim bilimine (Albert ve Beatty,2014; Prashar,2015), dil eğitimine (Hung, 2015; Helgeson, 2015) kadar farklı alanlarda uygulandığı tespit edilmiştir. Ancak Türkiye'de yapilan çalışmalar daha kısıtlı bir yelpaze oluşturmakta ağırlıklı olarak bilgisayar dersi uygulamaları (Görü-Doğan, 2015; Turan ve Göktaş, 2015) ya da teorik türde çalışmalara (Filiz ve Kurt, 2015; Karadeniz; 2015) rastlanmaktadır. Deneysel çalışmaların ise 
ağırlıklı olarak lisansüstü tezleriyle sınırlı kaldığ anlaşılmaktadır (Demiralay, 2014; Turan, 2015).

TES modeli Bergman ve Sams'in (2012) kimya dersine ilişkin oluşturdukları videoları öğrencileriyle paylaşmaları ilgiyi üzerinde toplamaya başlamıştır. Bergman ve Sams kapsamlı ve zorlu ders içeriğine sahip Kimya dersi için hazırladıkları videoları öğrencilerin derse gelmeden önce çalışırlarsa derslerin de öğrencilerin anlamakta zorlandıkları farklı kavramlara ayrılabileceğini ifade etmişlerdir. Bergman ve Sams'e (2012) ek olarak Dünyada ters yüz sınıf uygulamalarının kimya öğretimi alaninda (Schultz, Duffield, Rasmussen ve Wageman, 2014; Smith, 2013) yapıldığ1 bilinmekle birlikte Türkiye'de kimya öğretimine ilişkin herhangi bir TES çalışması tespit edilmemiştir. Bu yönüyle çalışmanın, bilgisayar derslerinin dışında bir ders olarak kimya dersi üzerinde ve deneysel bir yöntemle desenlenmesi açısından özgün olduğu düşünülmektedir. Araştırma sonuçlarının TES modelinin Türk kültüründe uygulanmasına ve ilgili alan yazına katkı sağlayacağı umulmaktadır.

$\mathrm{Bu}$ bağlamda, çalışmanın amacı kimya öğretiminde kullanılan TES modelinin öğretmen adaylarının erişileri ve görüşleri açısından incelenmesidir. $\mathrm{Bu}$ amaca bağlı olarak iki araştırma sorusu oluşturulmuştur.

1. Genel Kimya-1 dersinin öğretiminde kullanılan TES modelinin öğretmen adaylarının erişileri üzerinde anlamlı bir etkisi var mıdır?

2. Genel Kimya-1 dersinin TES modeliyle yürütülmesine ilişkin öğretmen adaylarının görüşleri nelerdir?

\section{YÖNTEM}

Araştırmanın amacı Genel Kimya-1 dersinin öğretiminde kullanılan TES uygulamalarının öğretmen adaylarının erişileri ve görüşleri açısından incelenmesidir. Çalışmada, nicel ve nitel veri toplama yöntemlerinin birlikte kullanılması yoluyla, araştırma sonuçlarını bütünleştirilmesine imkan sağlayan karma yöntem kullanılmıştır. Nicel ve nitel verilerin eşzamanlı olarak toplandığı bu çalışmada farklı iki paradigmaya yönelik araştırma soruları bulunması sebebiyle eşzamanlı çeşitleme karma araştırma yöntemi kullanılmıştır (Creswell, 2003). Eşzamanlı ya da yakınsayan desende nicel ve nitel veriler tek basamakta ve iki farklı süreçte toplanır, benzeşmeler ve ayrışmalar ortaya koyulmaya çalışılır (Creswell ve Clark, 2014). Araştırmanın nicel boyutunu öntestsontest kontrol gruplu yarı deneysel desen nitel boyutunu ise öğretmen adaylarıyla yapılan yüz yüze görüşmeler oluşturmuştur. Nicel veri toplama aracı olarak araştırmacılar tarafindan geliştirilen "Başarı Testi", nitel verilerin toplanmasında ve yine araştırmacılar tarafından geliştirilen yarı yapılandırılmış görüşme formu kullanılmıştır.

\section{1 Çalışma Grubu}

Çalışma, 2015-2016 güz döneminde Celal Bayar Üniversitesi Eğitim Fakültesi Fen Bilgisi öğretmenliği birinci sınıf öğretmen adaylarıyla gerçekleştirilmiştir. Araştırmanın örnekleminin seçiminde amaçlı örnekleme yöntemi kullanılmıştır. Örneklemin seçiminde deneklere kolay ulaşma ve sözü edilen öğrenim programının birden fazla şubesinin olması temel iki ölçüt olarak belirlenmiştir. Bu ölçütlere uyan 3 adet birinci sınıf Fen Bilgisi Öğretmenliği grubu tespit edilmiştir. Bu üç gruptan biri deney ve biri kontrol grubu olmak üzere iki grup rastgele seçilmiştir. Çalışma, Deney (N:21) ve Kontrol (N:18) gruplarında yer alan toplam 39 Fen Bilgisi öğretmen adayı ile yürütülmüştür. Çalışmaya katılan 39 öğretmen adayından 20'si kız 19'u erkektir.

\section{2 İşlem}

Çalışma 2015-2016 eğitim öğretim yılı güz döneminde Genel Kimya-1 dersi kapsaminda Atomun Elektronik yapısı ve Periyodik Çizelge ve Atom özellikleri konuları temel alınarak yürütülmüştür. Deney grubuna dersler TES modeline göre Kontrol grubunda ise ders anlatım ve etkinliklerin sınıf içinde yapıldığı gerek duyulması durumunda ödevler ve diğer 


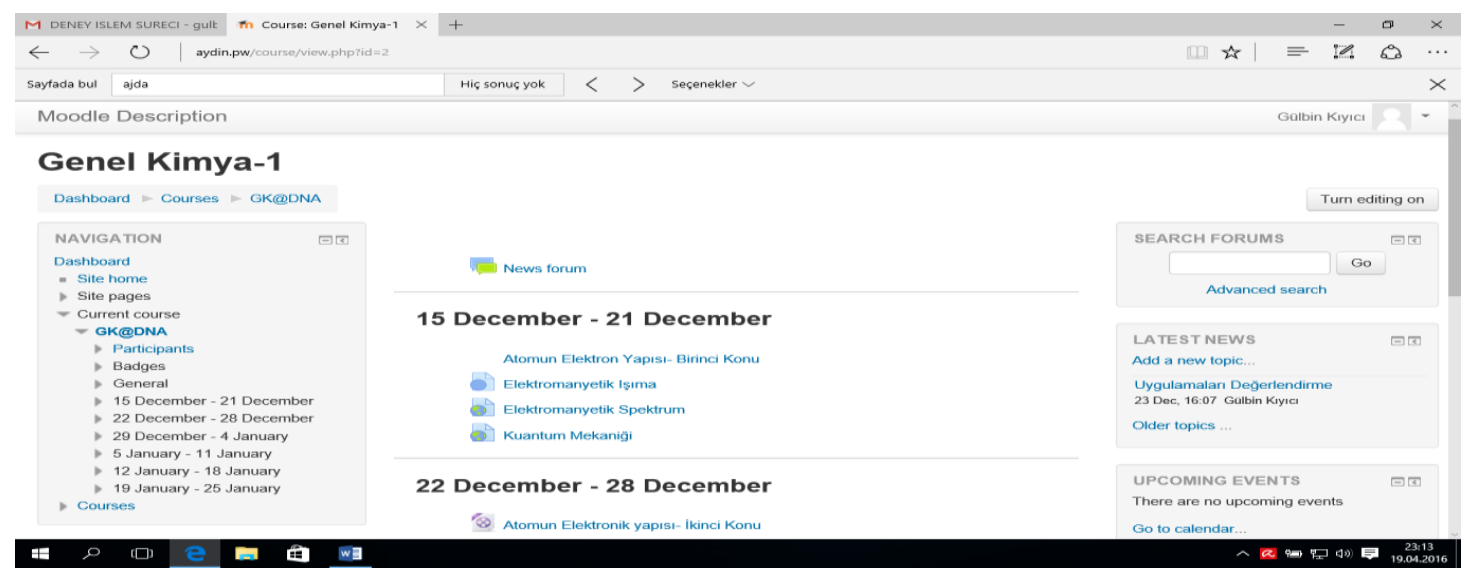

Şekil 1. Genel Kimya Dersine İlişkin Moodle Görüntüsü

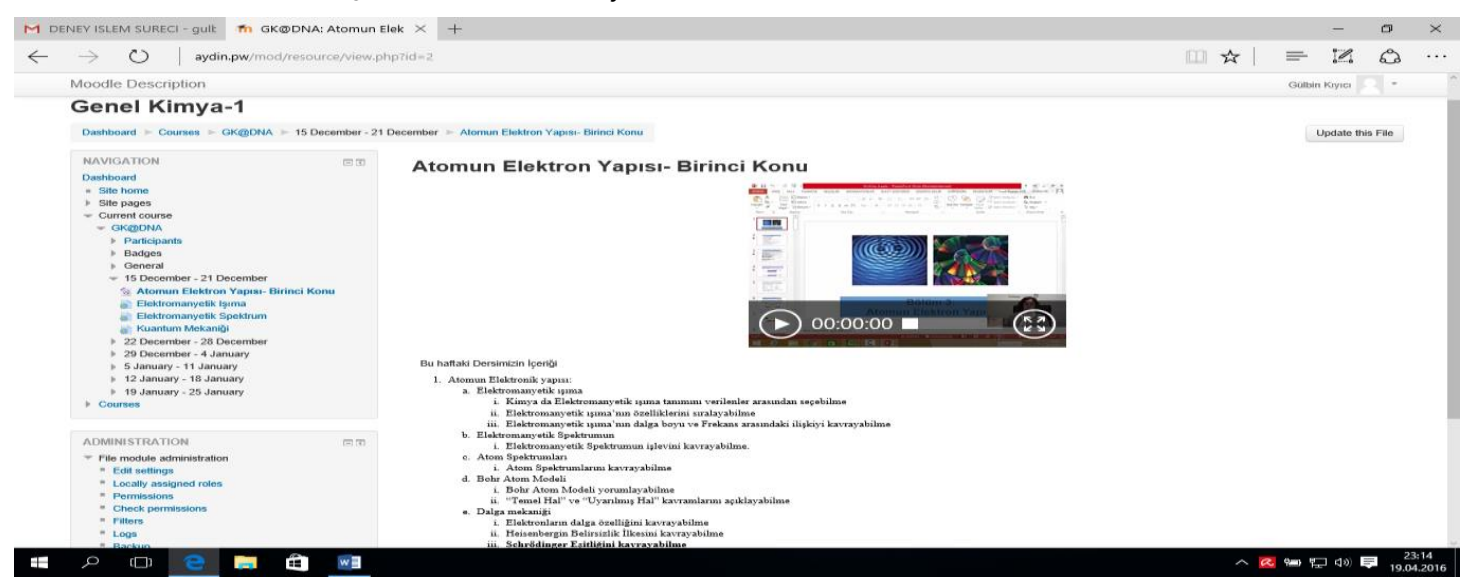

Şekil 2. Genel Kimya Dersine İlişkin Hazırlanan Videoların Moodle Görüntüsü

Her hafta birer tane olmak üzere 4 ders videosu Ders uygulamasını yürüten öğretim elemanı Moodle üzerinden öğretmen adaylarıyla tarafından yapılan her haftanın konusuna ait paylaşılmıştır. Hazırlanan videoların süreleri 17 ile 20 dakika arasında değişmektedir. Videolarda kullanilan sunumlar Genel Kimya 1 Dersi içeriğine bağlı kalınarak alınarak hazırlanmıştır. ders sunumu Camtasia Studio isimli program kullanılarak kayıt edilmiştir. Şekil 3 ve Şekil 4'te hazırlanan sunumlara ilişkin ekran görüntüleri paylaşılmıştır.

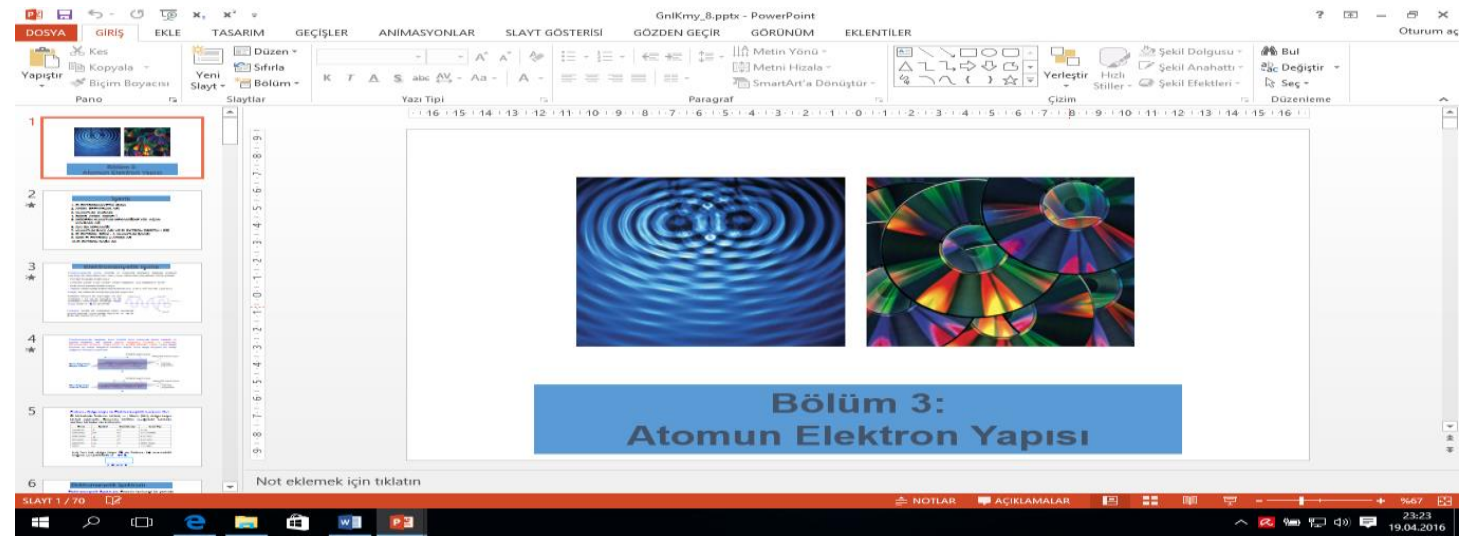

Şekil 3. Genel Kimya Dersine İlişkin Hazırlanan Sunumlara Ait Ekran Görüntüsü 


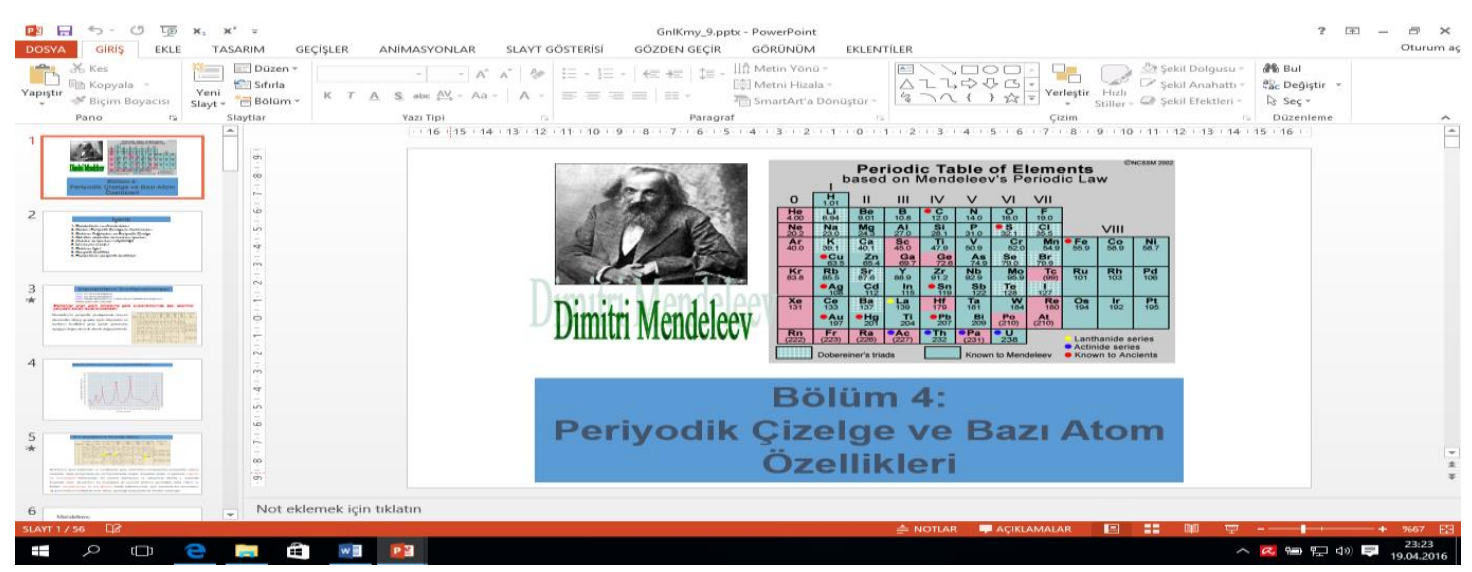

Şekil 4. Genel Kimya Dersine İlişkin Hazırlanan Sunumlara Ait Ekran Görüntüsü

Deney grubunda yer alan öğretmen adayları derslerden önce ilgili videoyu izlemişler konuyla ilgili anketi cevaplamışladır. Ders içi süreçler öğrencilerden gelen anket sonuçlarına göre düzenlenmiş, dersler tanılayıcı dallanmış ağaç uygulaması, kavram haritası hazırlanması, beyin fırtınası, rol oynama, öykü oluşturma, analoji, kavram karikatürü hazırlanması, şiir (akrostiş olabilir) yazma, slogan hazırlanması, reklam hazırlanması, hikaye hazırlanması, istasyon tekniği vb. aktif öğrenme teknikleri kullanılarak işlenmiştir. Uygulamaların sonunda Son Test olarak Deney ve Kontrol gurubuna Genel Kimya Başarı testi uygulanmıştır. Ayrıca deney grubunda yer alan öğretmen adaylarının TES uygulamalarına ilişkin görüşleri alınmıştır.

\subsection{Veri Toplama Araçları}

Deney ve kontrol gruplarına işlem öncesi ön test ve işlemler sonrasında da son test olarak araştırmacılar tarafından geliştirilen, "Genel Kimya Başarı Testi" ayrıca TES etkinliklerine ilişkin sürecin daha iyi açılanması amacıyla öğretmen adaylarına dört maddelik bir görüş formu uygulanmış ve elde edilen veriler analiz edilmiştir.

Genel Kimya Başarı Testi: Genel Kimya başarı testinin geliştirilmesi için ilk olarak Atomun Elektronik yapısı ve Periyodik Çizelge ve Atom özellikleri konularına ilişkin hedefler taksonomik olarak düzenlenmiştir. Başarı testi geliştirme aşamalarına bağlı olarak her bir kazanım için iki olmak üzere toplam 62 denemelik madde hazırlanmıştır. Oluşturulan maddelerin hedefleri ölçüp ölçmediği, kapsam geçerliğinin sağlayıp sağlamadığı ve anlaşılırlığı açısından bir alan uzmanı, bir program geliştirme uzmanı ve bir ölçme değerlendirme uzmanından uzman görüşü alınmıştır. Görüşler doğrultusunda denemelik maddelerden dokuz madde atılarak 53 maddelik denemelik forma ulaşılmıştır. Bu denemelik form 2015-2016 öğretim yılının Ekim ayında Celal Bayar Üniversitesi Eğitim Fakültesi Fen Bilgisi öğretmenliği 2. 3. ve 4. sınıflara devam eden toplam 214 öğretmen adayına uygulanmıştır. 30 maddelik Genel Kimya Başarı Testinin güvenirlik katsayısı .78, ayırıcılık gücü ortalaması .43, ortalama zorluk .56 olarak saptanmıştır.

Görüşme Formu: Denel işlem sonunda ters yüz edilmiş sınıf uygulamalarına ilişkin daha ayrıntılı verilere ulaşmak amacıyla öğretmen adaylarıyla yarı yapılandırılmış görüşmeler yapılmıştır. Görüşmeler sırasında öğretmen adaylarına dört açık uçlu soru yöneltilmiştir:

1. TES modelini, geleneksel sinif yaklaşımlarıyla karşılaştırdığınızda avantaj ve dezavantajları nelerdir?

2. TES uygulamalarında en çok sevdiğiniz ve en az sevdiğiniz yönler nelerdir? Neden?

3. TES modelinin etkili bir öğretim yaklaşımı olduğunu düşünüyor musunuz? Neden?

4. Size göre TES modeli başka hangi derslerde kullanılabilir? 


\subsection{Verilerin Analizi}

Deney ve kontrol gruplarındaki öğretmen adaylarının Genel Kimya Başarı testinden elde edilen öntest ve sontest başarı puanları arasında farkın olup olmadığı incelenmiştir. Çalışmada parametrik testler için gereken varsayımların karşılanamaması nedeniyle Mann Whitney U testi kullanılmıştır. Ayrıca öğretmen adaylarıyla TES uygulamalarına ilişkin görüşmeler sonucunda ulaşılan bulgular üzerinden betimsel analizler yapılmıştır. Nitel bulguların sunulmasında görüşme soruları tematik çerçeveyi oluşturmuştur.

\subsection{Geçerlik Güvenirlik}

Nitel verilerin analizi alan uzmanı iki araştırmacı tarafından yapılmıştır. Kodlar ve temalar üzerinde "görüş ayrıllı̆̆ı" olan ve "görüş birliğii" sağlanan konular tartışılmış buradan hareketle gerekli düzenlemeler yapılmıştır. Güvenirlik katsayısının hesaplanmasinda Miles ve Huberman'ın (1994) önerdiği güvenirlik formülü kullanilmıştır. Hesaplamalar sonucunda

Tablo 2. Deney ve Kontrol Grubu Genel Kimya Başarı Testi Öntest Puanların Mann-Whitney U testi Sonuçları

\begin{tabular}{lccccc}
\hline Grup & $\mathrm{n}$ & $\begin{array}{c}\text { Sira } \\
\text { Ortalaması }\end{array}$ & $\begin{array}{c}\text { Sira } \\
\text { Toplami }\end{array}$ & $\mathrm{U}$ & $\mathrm{P}$ \\
\hline Deney & 21 & 17,83 & 374.50 & 143.500 & 0.202 \\
Kontrol & 18 & 22,53 & 405.50 & & \\
\hline
\end{tabular}

Tablo 2'de öğretmen adaylarının öntest olarak kullanılan Genel Kimya Başarı Testinde yaptıkları doğru sayılarının sıra ortalamaları arasındaki farkın 4,7 olduğu tespit edilmiştir. Farkın anlamlı olup olmadığını belirlemek için Mann Whitney U testi yapılmıştır. Yapılan test sonucunda deney ve kontrol grubunda yer alan öğretmen adaylarının 30 maddelik öntestteki

doğru cevap sayıları arasında anlamlı bir farklılık saptanmamıştır ( $\mathrm{U}=143.5, \mathrm{p}>.05)$. $\mathrm{Bu}$ sonuç öğretmen adaylarının Genel Kimya ders başarıları bakımından homojen bir yapıya sahip olduklarının bir göstergesi olarak kabul edilebilir. Deney ve Kontrol Grubu Genel Kimya Başarı Testi Sontest Puanların Mann-Whitney U testi Sonuçları Tablo 3'te verilmiştir.

Tablo 3. Deney ve Kontrol Grubu Genel Kimya Başarı Testi Sontest Puanların Mann-Whitney U testi Sonuçları

\begin{tabular}{lccccc}
\hline Grup & $\mathrm{n}$ & $\begin{array}{c}\text { Sira } \\
\text { Ortalaması }\end{array}$ & $\begin{array}{c}\text { Sira } \\
\text { Toplamı }\end{array}$ & $\mathrm{U}$ & $\mathrm{p}$ \\
\hline Deney & 21 & 23,74 & 498,50 & 110,500 & 0.026 \\
Kontrol & 18 & 15,64 & 281,50 & \\
\hline Tablo 3 incelendiğinde kontrol grubunun Genel & \multicolumn{2}{c}{ deney grubunun sontest sira ortalamasının 23.74 } \\
Kimya Başarı Testi sontest sıra ortalaması 15.64 & \multicolumn{4}{c}{ sira ortalamaları arasındaki farkın ise 8.1 olduğu }
\end{tabular}


anlaşılmaktadır. Farkın anlamlı olup olmadığını belirlemek için Mann Whitney $U$ testi sonucunda deney ve kontrol grubunda yer alan öğretmen adaylarının sontesteki doğru cevap sayıları arasındaki farkın deney grubu lehine anlamlı olduğu görülmektedir (U=110.5, p>.05). Bu sonuçtan hareketle deney grubunda Genel Kimya-1 dersinin öğretiminde kullanılan TES modelinin öğretmen adaylarının erişileri üzerinde anlamlı bir etkisi olduğu söylenilebilir.

\subsubsection{TES Modeliyle İlgili Öğretmen Adaylarının Görüşlerine İlişsin Bulgular:}

Genel Kimya-1 dersinin ters yüz edilmiş sınıf yöntemiyle yürütülmesine ilişkin öğretmen adaylarının görüşlerine ilişkin bulgular Tablo 4, Tablo 5, Tablo 6'da sunulmuştur. Nitel bulguların sunulmasında görüşme soruları tematik çerçeveyi oluşturmuştur.

Görüşme Sorusu: TES modelini, geleneksel yöntemlerle karşılaştırdı̆̆ınızda avantaj ve dezavantajlarn nelerdir?

Tablo 4. Ters Yüz Edilmiş Sınıf Modelinin Avantaj ve Dezavantajları

\begin{tabular}{lll}
\hline Kategori & Kod & $\mathrm{f}$ \\
\hline Avantaj & Eğlenceli öğrenme & 7 \\
& Derse hazırlıklı gelme & 5 \\
& Bilginin pekiştirilmesi & 5 \\
Dezavantajları & Anında dönüt alamama & 6 \\
& Çok fazla zaman alması & 5 \\
& Dezavantajı yok & 5 \\
\hline
\end{tabular}

Öğretmen adaylarının TES modeli

uygulamalarının avantajlarını en çok " Eğlenceli öğrenme " $(\mathrm{N}=7)$, “ Derse hazırlıklı gelme" $(\mathrm{N}=5)$, “ Bilginin pekiştirilmesi” $(\mathrm{N}=5)$ olarak belirtmişlerdir. Bu bulgulara yönelik öğretmen adaylarının ifadeleri ise şöyledir:

"Dersler daha eğlenceli, verimli ve bize birçok teknik yöntem kazandırdı"(Ö14).

"Somut şeyleri ele alıp ve uygulama yaptığımız için akılda daha çok kalıcı olacağını düşünüyorum. Çünkü yapmış olduğumuz uygulamalarımız sınıf içinde çok güzeldi, çok eğlendik."(Ö16).

“Bir öğrenci yüzünden dersin işlenişi bozulmuyor. Ya da bir cümleyi kaçırdığın zaman dersin işleyişini bozmak yerine videoyu geri sarıp tekrar izleyebiliyoruz."(Ö1).

“Videolar çok ilginç ve merak uyandırıcı derse hazır gelmemizi derse etkin katılım yapmamızı

sağlıyor bu da bilgilerimizi kalıcı hale getiriyor." (Ö3)

Öğretmen adaylarının ters yüz edilmiş sınıf uygulamalarının dezavantajları " Anında dönüt alamama" (N=4), "Çok fazla zaman alması" $(\mathrm{N}=4)$, "Etkinliklerle kavramları eşleştirememe" $(\mathrm{N}=3)$ "Dezavantajı yok" $\quad(\mathrm{N}=5) \quad$ şeklinde belirtmişlerdir. Bu kategori içinde verilebilecek öğretmen adaylarının görüşleri ise şöyledir:

“Videoyu izlerken aklımıza takılan soruları o an cevap alamıyoruz. Genellikle öğrendiğimiz kavramlar yabancı olduğu için anlamakta zorluk çekiyorum.(Ö 7).

“Belki biraz eski yöntemlere alışık olduğumuz için konu anlatılırken hocaya bir şey soramamak bizi rahatsı edebiliyor."(Ö 1)

Görüşme Sorusu: TES uygulamalarında en çok sevdiğiniz ve en az sevdiğiniz yönler nelerdir? Neden?

Tablo 5. Ters Yüz Edilmiş Sınıf Modeli Uygulamalarında Sevilen ve Sevilmeyen Yanlar

\begin{tabular}{llc}
\hline Kategori & Kod & $\mathrm{f}$ \\
\hline En çok sevilen & Etkinlik yapma & 13 \\
& Kalıcılık sağlama & 4 \\
& Grup arkadaşlarıly uygulamalar & 4 \\
En az sevilen & Farklı örnek soru soramamak & 3 \\
& Zaman yetersizliği & 2 \\
& Öğretim elemanının derse fazla katılmaması & 1 \\
\hline
\end{tabular}


Öğretmen adayları tarafından TES uygulamalarına ilişkin en çok sevilen yanları "Etkinlik yapma" (N=13), "Kalıcılık sağlama" $(\mathrm{N}=4)$, "Grup arkadaşlarıyla uygulamalar" $(\mathrm{N}=4)$ olarak belirtmişlerdir. $\mathrm{Bu}$ kategori altında öğretmenlerden alınan ifadeler ise aşağıda verilmiştir:

"Yapılan etkinliklerle konuların daha iyi pekiştirilmesi beni mutlu etti. Çünkü bu sayede kavramları karakterize ederek aklımızda daha kolay kalmasını sağladık."(Ö=7).

"Derste çeşit çeşit etkinlik yapılması çok eğlenceli ve çok faydalı."(Ö5).

“Karikatür çizerek konuyu konuşmalar şeklinde anlatmak bence çok etkiliydi."(Ö4)

"Sınıf içi etkinliklerde sürekli etkin olmamız ve herkesin görüşünü eşit bir şekilde ortaya koyması çok güzeldi." (Ö18)

Öğretmen adayları tarafından ters sınıf uygulamalarına ilişkin en az sevilen yanlar ise "Farklı örnek soru soramamak" (N=3), Zaman yetersizliği $(\mathrm{N}=2), \quad$ Öğretim elemanının derse fazla katılmaması $(\mathrm{N}=1)$ olarak tespit edilmiştir. $\mathrm{Bu}$ kategoriye ilişkin öğretmen adaylarının görüşlerinden bazıları şöyledir:

“ Konu anlatılırken hocaya dersle ilgili başka örnek soru soramamak." (Ö1).

“ Etkinliklerin bazılarında sürenin yetersiz olması."(Ö4).

Görüşme Sorusu: TES modelinin etkili bir öğretim yöntemi olduğunu düşünüyor musunuz? Neden?

TES modelini 21 öğretmen adayından 18'i etkili bulurken 3 öğretmen adayı yöntemi etkili bulmadıklarını ifade etmişlerdir. Etkili bulan öğretmen adaylarından bazılarının görüşleri şöyledir:

"Videolarda hocamızın anlatımlarını takip etmek çok motive edici, hem okuyarak, hem dinleyerek, hem de not alarak hazırlanmamızı ve sinıfta uygulamalar yapmamızı sağlaması açısından ters yüz sınıf uygulamalarının çok etkili olduğunu düşünüyorum." (Ö8)

"Evet etkili olduğunu düşünüyorum. İlginç olduğu için merak uyandırıyor, önceden hazırlıklı geliyoruz, bu bizim için bilgileri kapmamızda avantaj oluyor."(Ö11)

"Video ve sunumlar sayesinde derse hazırlıklı geliyoruz derslerde konuyla ilgili şiir, hikaye yazıyor, karikatürler yapıyoruz bunların öğrendiklerimizi pekiştirdiğini düşünüyorum. Ayrıca bu etkinliklerin çok işimize yarayacağını, ileride hitap edeceğimiz yaş grubunun da dikkatini çeken etkinlikler olduğunu düşünüyorum." (Ö13) ifadesini kullanmıştır.

Bunların yanı sıra TES uygulamalarını etkili bulmadığını belirten öğretmen adayları ise gerekçelerini şu şekilde sıralamışlardır:

"Ters yüz sınıf yönteminin bana uygun olmadığını düşünüyorum." (Ö19)

“Ters yüz öğrenme sözel derslerin anlatımında çok etkili ancak sayısal konularda bence yetersiz soruların çözümünü çok daha fazla hoca yapmalı." (Ö 15)

“Bazı haftalarda çok yoğun olduğum için videoları izlemek çok zor oluyor konuları iyi kavrayamadığımı düşünüyorum." (Ö 17)

Görüşme Sorusu: Size göre TES uygulamaları başka hangi derslerde kullanılabilir?

Tablo 6. TES Uygulamalarının Farklı Derslerde Kullanımına İlişkin Görüşler

\begin{tabular}{ll}
\hline Dersler & $\mathrm{n}$ \\
\hline Fizik & 7 \\
Biyoloji & 6 \\
Tarih & 6 \\
Türk Dili & 5 \\
Eğitim Bilimleri & 5 \\
İngilizce & 3 \\
Laboratuvar & 1 \\
Her ders & 2 \\
\hline
\end{tabular}


Tablo 6 incelendiğinde öğretmen adaylarının TES modelinin hangi derslerde kullanılabileceğine ilişkin soruya ilk sıralarda fizik, biyoloji ve tarih derslerini belirttikleri anlaşılmaktadır. Bu dersler sayısal ve sözel dersler olarak sınıflandırıldığında ise öğretmen adaylarının çoğunlukla sözel dersleri daha çok belirttikleri söylenebilir.

\section{TARTIŞMA VE SONUÇ}

Genel Kimya-1 dersinin öğretiminde kullanılan TES modelinin öğretmen adaylarının erişileri ve görüşleri açısından incelendiği bu araştırmanın ilk bulgusu erişilere ilişkindir. Ulaşılan sonuçlar, Fen Bilgisi öğretmen adaylarının Genel Kimya 1 dersinin erişilerinde deney grubu lehine anlamlı bir farkın olduğunu göstermiştir. Alanyazın incelendiğinde bu bulguyu destekleyen çalışmalara rastlanmıştır. Örneğin, Seery, (2015) kimya öğretiminde ters yüz edilmiş öğrenmeyi kullanan araştırma raporlarını incelemiştir. Araştırma sonuçları genel anlamda TES modelinin öğrencilerin kimya ders başarısı üzerinde olumlu etkiye sahip olduğunu ortaya koymaktadır. Ayrıca alanyazında, TES modelinin akademik başarıyı arttırdığını gösteren farklı çalışmalara da yer almaktadır (Davies, Dean ve Ball, 2013; MacKinnon, 2015; Prashar, 2015; Wilson, 2013).

Benzer bir biçimde Sharma, Lau, Doherty, Harbutt, (2015) sağlık alanında eğitim alan üniversite öğrencileriyle yürüttükleri çalışmalarında, geleneksel yöntemlerle karşılaştırıldığında TES modelinin lehinde sonuçlara ulaşmışlardır. Ek olarak, Detroit yakınlarındaki Clintondale lisesinde yürütülen TES uygulamaları sonucunda öğrencilerin başarısızlık düzeyi \%44'ten \%13 düştüğü tespit edilmiştir (Palmer, 2015). Albert ve Beatty, (2014) ise yönetime giriş dersinin yürütülmesinde kullandıkları TES modelinin geleneksel yöntemlerle karşılaştırıldığında üniversite öğrencilerinin akademik başarıları üzerinde daha etkili olduğu sonucuna ulaşmışlardır.

TES modelinin yürütülmesine yönelik öğretmen adaylarının görüşleri araştırmanın bir diğer bulgusunu oluşturmaktadır. Görüşmede yöneltilen, ters yüz edilmiş sınıf yöntemini, geleneksel yöntemlerle karşılaştırdığınızda avantaj ve dezavantajları nelerdir? sorusuna öğretmen adayları avantaj olarak, tekrar tekrar dersi izleyebilme, derse hazırlıklı gelme, bilginin pekiştirilmesi, uygulama yapmaya uygun olması, eğlenceli öğrenme, teknoloji kullanmaya yardımcı olma, dezavantaj olarak, anında dönüt alamama, çok fazla zaman alması, problem çözümlerinin yetersizliği cevaplarını vermişlerdir. TES uygulamalarının en çok sevdiğiniz ve sevmediğiniz yanları nelerdir? sorusu karşısında ise en sevilen yanların etkinlik yapma, kalıcılık sağlama, grup arkadaşlarıyla yapılan uygulamalar, olduğu sevilmeyen yanların, Farklı örnek soru soramamak zaman yetersizliği, öğretmenin derse fazla katılmaması olduğu belirlenmiştir.

$\mathrm{Bu}$ bölümde ulaşılan bulgular gerek yurtdışı gerekse yurtiçi alan yazınla benzerlik göstermektedir (Görü-Doğan, 2015; Love, Hodge, Grandgenett ve Swift, 2014; Smith, 2013; Turan ve Göktaş, 2015). Örneğin, Smith, (2013) kimya öğretiminde kullandığı TES modelinin, öğrenciler tarafindan dersten önce sunumlara ulaşılması, ders içi süreçlerin sorulara ve problem çözme etkinliklerine ayrılması yönünden olumlu karşılandığını belirtmektedir. Benzer bir biçimde Love, Hodge, Grandgenett ve Swift, (2014) üniversite öğrencileri ile yürüttükleri lineer cebir dersini TES modelini kullanarak işlemişlerdir. Sürecin sonunda öğrencilerden aldıkları görüşler bu araştırma bulgularıyla paralellik göstermektedir. Araştırmacılar, öğrencilerin \%74'nün TES uygulamalarına ilişkin olumlu tutum içerisinde olduklarını, sınıf içi etkinlikleri genel anlamda olumlu karşıladıklarını, sınıf içi etkinlerin bilgileri hatırda tutmaya yardımcı olduğunu, etkileşimli sınıf ortamının öğrencilerin dikkatini yoğunlaştırmalarını sağladığını, öğrencilerin \%78'i grup çalışmalarının öğrencileri sosyalleştirdiğini, sınıf arkadaşlarını daha iyi tanımalarına fırsat sağladığını, tüm bunların eğlenceli bir öğrenme ortamı sağladığını ifade etmişlerdir. 
Bu noktada bir başka önemli bulgu, öğretmen adaylarının gerek dezavantaj gerekse sevilmeyen yön olarak TES uygulamalarında öğretmenin geri planda kalması, videolar izlenirken öğretmenin anında dönüt vermemesi, öğretmenin daha fazla aktif olması gibi öğretmen merkezli talepleri dile getirmeleridir. Bu durum öğretmen adaylarının eğitim aldıkları, alıştıkları öğretmen merkezli yaklaşımları sürdürme istekleriyle açılanabilir. Nitekim Öğretmen adayı 1 "Belki biraz eski yöntemlere alışık olduğumuz için konu anlatılırken hocaya bir şey soramamak bizi rahatsız edebiliyor."(Ö 1) ifadesiyle bu durumu özetlemektedir. Bu bulgunun da gerek yurt dışı gerekse yurt içi araştırma bulgularıyla benzerlik gösterdiği söylenebilir (Görü-Doğan,2015; Love, Hodge, Grandgenett ve Swift, 2014; Smith, 2013; Turan ve Göktaş, 2015).

Araştırmanın bir başka bulgusu TES uygulamalarının öğretmen adayları tarafından etkili bulunup bulunmamasına ilişkindir. Araştırma sonuçları öğretmen adaylarının büyük bir kısmının uygulamaları derse hazırlıklı gelmeyi sağlama, eğlenceli merak uyandırıcı olma, pekiştirici olma açısından TES modelini etkili bulmuşlardır. Diğer taraftan az sayıda da olsa bazı öğretmen adaylarının kendilerine uygun olmadığı, hocanın daha çok soru çözmesinin kendileri için daha iyi olduğu, videoları yoğunluk nedeniyle izlemekte zorluk çekmeleri vb. nedenlerle ters yüz edilmiş sınıf uygulamalarını etkili bulmamışlardır. Benzer bir biçimde, Love, Hodge, Grandgenett ve Swift'e (2014) ait araştırmada üniversite öğrencilerinin $21 \%$ geleneksel yöntemi TES uygulamalarına tercih etmiştir. Plammer (2015) ise matematik öğretiminde TES modelinin kullandığ çalışmasında üniversite öğrencilerinden bazılarının "TES uygulamalarının utangaç, konuşmakta ve yardım istemede zorluk yaşayanlar için uygun bir yöntem olmadığını" ve "TES modelinin kendisine uygun olmadığını" ifade ettiklerini belirtmiştir. Bunun üzerine araştırmacı öğrenme stilleriyle TES uygulamalarında gösterilen başarıları karşılaştırmış ancak bir ilişki bulamamıştır.
Ancak araştırmacı bu sonucun küçük bir gruba ait olduğunun unutulmaması gerektiğini vurgulamaktadır.

Bir başka görüşme sorusu olan, Size göre TES modelinin uygulamaları hangi derslerde kullanılabilir? sorusuna ise öğretmen adayları, fizik, biyoloji, tarih, Türk Dili, eğitim bilimleri gibi derslerde de ters yüz edilmiş sınıf yönteminin kullanılabileceği cevabını vermişlerdir. Verilen cevaplar sözel ve sayısal olarak oranlandığında ağırlıklı olarak sözel derslerin öğretmen adayları tarafından daha fazla dile getirildiği ancak, matematik dersinin hiçbir öğretmen adayı tarafından belirtilmediği tespit edilmiştir.

$\mathrm{Bu}$ bağlamda yurtdışı alanyazın incelendiğinde TES modelinin, matematikten, dile, sağlıktan, edebiyata çok geniş bir kullanım alanına sahip olduğu anlaşılmaktadır (Albert ve Beatty, 2014; Helgeson, 2015; Hung, 2015; Maxson ve Szanislo, 2015; Prashar,2015; Sharma, Lau, Doherty, Harbutt, 2015; Youngkin, 2014). Ancak, yine de TES modeline yönelik yapılan çalışmaların yetersizliği düşünüldüğünde farklı ders ve düzeylerde modelin etkili olup olmadığının söylenebilmesi için daha uzun bir yolun olduğu söylenebilir (Naccarato ve Karakok, 2015).

Sonuç olarak, bu çalışma ile TES modelinin öğretmen adaylarının Genel Kimya ders başarısını arttırdığı tespit edilmiştir. Ayrıca öğretmen adayları TES modeli uygulamalarına ilişkin önemli oranda olumlu görüş belirttikleri ve yöntemi etkili buldukları saptanmıştır. Buradan hareketle, ilk olarak, daha doğru değerlendirmeler yapabilmek için, TES modeli ile değişik derslere ait öğretim programları arasındaki ilişkinin farklı düzey ve değişkenler işe koşularak araştırılabilir. İkinci olarak, gerek yurtdışında gerek yurtiçi ilgili alanyazında deneysel çalışmaların azlığı dikkat çekmektedir. $\mathrm{Bu}$ bağlamda, farklı deneysel araştırmalar gerçekleştirilebilir. Son olarak TES modelinin Türk Eğitim Sistemi ve kültürüne uygunluğu açısından ele alan daha fazla çalışmanın 
yapılmasının bir ihtiyaç olduğu

düşünülmektedir.

\section{Kaynakça}

Albert, M., \& Beatty, B. J. (2014). Flipping the classroom applications to curriculum redesign for an introduction to management course: Impact on grades. Journal of Education for Business, 89, 419424

Bergman, J. \& Sams, A. (2012). Flip your classroom: Reach every student in every class every day. Oregon: International Society for Technology in Education.

Bishop, J.L. \& Verlager, M.A. (2013). The Flipped Classroom: A Survey of the Research. 120th ASEE $\begin{array}{lllll}\text { Annual } \quad \text { Conference } \quad \& \quad & \text { Exposition. } & \text { ErişimTarihi: } & 02.2016\end{array}$ http://www.studiesuccesho.nl/wpcontent/uploads/2014/04/flipped-classroom-artikel.pdf

Creswell, J. W. (2003). Research design qualitative, quantative and mixed methods approaches. California: Sage Pub.

Creswell J. W., \& Clark, V. L. P. (2014) Karma yöntem desen seçimi(Çev. A. Delice). Karma yöntem araştırmaları tasarımı ve yürütülmesi (Çev. Ed. Y. Dede, S. B. Demir) Anı Yayıncılık

Demiralay, R. (2014). Evde Ders Okulda Ödev Modelinin Benimsenmesi Sürecinin Yeniliğin Yayılımı Kuramı Çerçevesinde İncelenmesi. Yayımlanmamış Doktora Tezi. Gazi Üniversitesi, Ankara.

Davies, R. S., Dean, D. L., \& Ball, N. (2013). Flipping the classroom and instructional technology integration in a college-level information systems spreadsheet course. Educational Technology Research and Development, 61(4), 563-580.

Filiz, O. \& Kurt, A.A (2015). Flipped Learning: Misunderstandings and the Truth, Journal of Educational Sciences Research,5(1), 215-229

Ford, P. (2015). Flipping a Math Content Course for Pre-Service Elementary School Teachers. PRIMUS, 25(4), 369-380,

Görü Doğan, T. (2015). Sosyal medyanın öğrenme süreçlerinde kullanımı: Ters-yüz edilmiş öğrenme yaklaşımına ilişkin öğrenen görüşleri. Açıköğretim Uygulamaları ve Araştırmaları Dergisi, 1(2), 2448.

Karadeniz, A. (2015). Ters-yüz edilmiş sınıflar. Ĕ̆gitim ve Öğretim Araştırmaları Dergisi, 4(3), 322-326.

Love, B. Hodge, A., Grandgenett N. \& Swift A. W. (2014). Student learning and perceptions in a flipped linear algebra course, International Journal of Mathematical Education in Science and Technology, 45(3), 317-324.

MacKinnon, G. (2015). Determining useful tools for the flipped science education classroom, Contemporary Issues in Technology and Teacher Education, 15(1), 44-55

Naccarato, E. \& Karakok, G. (2015). Expectations and implementations of the flipped classroom model in undergraduate mathematics courses, International Journal of Mathematical Education in Science and Technology, 46(7), 968-978

Orhan, D., Kurt, A. A., Ozan, Ş., Vural, S. S. ve Türkan, F. (2014). Ulusal eğitim teknolojisi standartlarına genel bir bakış. Karaelmas Ĕ̆gitim Bilimleri Dergisi, 2(1), 65-79.

Palmer, K. (2015). Flipping a Calculus Class: One Instructor's Experience. PRIMUS: Problems, Resources, and Issues in Mathematics Undergraduate Studies, 25(9-10), 886-891.

Prashar, A. (2015). Assessing the flipped classroom in operations management: A pilot study, Journal of Education for Business, 90(3), 126-138

Prensky, M. (2001). Digital natives, digital immigrants part 1. On the horizon, 9(5), 1-6. 
Sage, M. \& Sele, P. (2015). Reflective journaling as a flipped classroom technique to increase reading and participation with social work students, Journal of Social Work Education, 51(4), 668-681

Schultz, D., Duffield S., Rasmussen S. C. \& Wageman J., (2014). Effects of the Flipped Classroom Model on Student Performance for Advanced Placement High School Chemistry Students, J. Chem. Educ., 91, 1334-1339.

Seery, M. K. (2015). Flipped learning in higher education chemistry: emerging trends and potential directions. Chemistry Education Research and Practice,16, 758-768

Sharma, N., Lau, C. S., Doherty, I., \& Harbutt, D. (2015). How we flipped the medical classroom. Medical Teacher, 37(4), 327-330

Smith J. D., (2013). Student attitudes toward flipping the general chemistry classroom. Chem. Educ. Res. Pract.,14, 607-614.

Turan, Z.,(2015).Ters Yüz Sınıf Yönteminin Değerlendirilmesi ve Akademik Başarı, Bilişsel Yük Ve Motivasyona Etkisinin İncelenmesi, Yayımlanmamış Doktora Tezi, Atatürk Üniversitesi, Erzurum.

Turan, Z. ve Göktaş, Y. (2015). Yükseköğretimde Yeni Bir Yaklaşım: Öğrencilerin Ters Yüz Sınıf Yöntemine İlişkin Görüşleri. Yükseköğretim ve Bilim Dergisi, 5(2), 156-164.

Yıldırım, A. \& Şimşek, H. (2005). Sosyal Bilimlerde Nitel Araştırma Yöntemleri. Ankara: Seçkin Yayıncılık.

Wilson, S. G. (2013). The flipped class: a method to address the challenges of an undergraduate statistics course. Teaching of Psychology, 40, 193-199.

Youngkin, C. A. (2014). The Flipped Classroom: Practices and Opportunities for Health Sciences Librarians. Medical Reference Services Quarterly, 33:4, 367-374, DOI: 0.1080/02763869.2014.957073 


\section{EXTENDED SUMMARY}

The developments in the field of science and technology forces all fields from the economy to health; from the arts and literature to important changes. One of the other field is education which has been affected from the technological developments and is expected to transform its paradigms. Children and youngsters called as z generation and digital citizens take the most important share. The most important feature of these individuals is that they can adapt technology to their lives more swiftly. In terms of their qualities, it is seen as a necessity that education Technologies to be used in bringing up these students who differentiate from the former generation in an important rate. (Orhan, Kurt, Vural \& Türkan, 2014)

In the field of education technology, one of the methods that has been used recently is the flipped classroom. Flipped classroom is a process of education which is teacher centered and the traditional education understanding restricted with walls is flipped and blended. In a flipped classroom, students watch and study lesson videos and other e-materials before at home, at dormitory prepared by the teacher and in classroom they structure by absorbing a subject with different active activities. In this respect, it is a method which reverses the traditional education process (Bishop \& Verlager, 2013; Görü Doğan, 2015)

The aim of this research is a study of the flipped classroom used in chemistry education in terms of the academic achievement and views of the prospective teachers. Based on this aim, it has been formed two research questions: 1 . Is there a meaningful effect of the flipped classroom used in the general chemistry lesson on the prospective teachers academic achievement? 2. What are the views of the prospective teachers regarding with the implementation of the flipped classroom?

In the study, by way of the quantitative and qualititative data gathering method, it has been used the mix method which provides an opportunity in integrating the research results. (Creswell, 2003). Including the Research experiment (N:21) and Control (N:18) groups, it has been carried out with the 39 prospective science teachers. Of the 39 prospective teachers who participated in the workout, the 20 of them are girls, and 19 of them are boys. "General Chemistry Achievement Test" which have been developed by the reserchers before process as the pre test and after the process post test o the experiment and control groups, also with the aim of flipped classroom activities related process in mind, has been practiced to the prospective teachers in the form of a view form of four articles and the resulting datum have been analized.

It has been determined that the variation between the correct answer numbers that they have achived in the General Chemistry Achievement Test and the mean rank is 4.7. In order to understand whether the variation is meaningful or not Mann Whitney $U$ Test has been made. As a result of the test having been made, no meaningful variation between the correct answer numbers in the pre test of 30 articles who are included in both the experiment and control groups. ( $\mathrm{U}=143.5, \mathrm{p}>.05$ ). This result has been accepted as a sign that the prospective teachers have a homogen structure in terms of the General Chemistry achievement results. As a result of the post test practice, it has been determined that the variation between the General Chemistry Achievement Test post test mean rank of the control group is 15.64 and post test mean rank is 23.74 of the experiement group and mean rank is 8.1. In order to determine whether the variation is meaningful or not, at the end of the Mann Whitney U Test it has been determined that the difference between the correct answer numbers in the post tests of the prospective teachers included in the experiment and control groups are in favor of the experiment group. (U=110.5, $\mathrm{p}>$.05). Based on this, it can be said there is an effect of the flipped classroom of the General Chemistry-1 in the experiement group on the academic achievement of the prospective teachers.

Additively, semi-structured meetings have been made regarding the flipped classroom. It has been determined that to such a question as to "What are the advantages and disadvantages when you 
compare the flipped classroom to the traditional methods?", they answer as the advantage that watching the lesson repetitively, enjoyable learning, coming to class after having prepared, the reinforcement of the information, and as the disadvantage that not getting instant feedback, and that it takes too much time. In the face of the question being asked as to "What are the sides that you like and dislike?" they answered that doing activities, providing continuance, the practices with the group friends, that the sides they do not like they answered that not asking different example questions, lacking time, and not participating of the instructor to the lesson. In the face of the question being asked as to the "Do you think that flipped classroom is an effective teaching method?" they answered in positive to a large extent. Lastly, in the face of the question asked "In which lessons the flipped classroom can be used according to you?" the prospective teachers gave the answer that the flipped method can be used in also physics, biology, history, literature, and education sciences.

As a result, with this study, it has been determined that the flipped classroom has enhanced the lesson sucess of the General Chemistry. Moreover, it has also been found that the prospective teachers have opined in positive regaridng the flipped classroom and they have found the method very effective. Based on this, firstly, in order to be able to make more correct evaluations, the relationship between the flipped classroom and the teaching methods belonging to different lessons can be searched by way of using different levels and variables. Secondly, it attracts notice in both abroad and at home in the related field the scantiness of the experimental studies. In this context, different researches can be made. As a last word, it has been tought that there is a need to make more reseaches which deal with that the flipped classroom with regard to Turkish Education System and culture. 